\title{
Photosynthetic tolerances to desiccation of tropical intertidal seagrasses
}

\author{
Mats Björk ${ }^{1, *}$, Jacqueline $\mathrm{Uku}^{2}$, Andreas Weil ${ }^{3}$, Sven Beer ${ }^{3}$ \\ 'Botany Department, Stockholm University, 106 91, Stockholm, Sweden \\ ${ }^{2}$ Kenya Marine and Fisheries Research Institute, PO Box 81651, Mombasa, Kenya \\ ${ }^{3}$ Department of Plant Sciences, Tel Aviv University, Tel Aviv 69978, Israel
}

\begin{abstract}
The aim of the present study was to investigate whether tropical intertidal seagrasses were better adapted to tolerate desiccation than subtidally growing seagrasses. To do this, the photosynthetic performance of 8 seagrass species, growing from the upper intertidal to the shallow subtidal in Zanzibar, East Africa, was studied during the event of air exposure and the subsequent rehydration. Photosynthetic efficiencies were measured by pulse amplitude modulated (PAM) fluorometry as effective electron quantum yields of photosystem II ( $Y$ ) since it had recently been shown that this measure parallels rates of $\mathrm{O}_{2}$ evolution for several species under a defined irradiance. Contrary to our expectations, it was found that the shallow intertidal species were in general more sensitive to desiccation than the deeper species. This was expressed both as a faster decline in $Y$ at decreasing water contents and as an inability to regain full photosynthetic rates during rehydration following even mild desiccation, as compared with the deeper-growing species. One exception was the subtidally growing Syringodium isoetifolium, which was very sensitive to desiccation. The 2 species which grow highest up in the intertidal zone, Halophila ovalis and Halodule wrightii, may not desiccate much in situ during low tide because the leaves lie flat on the moist sand and, for the latter species, overlap one another so as to minimise water loss. Thus, it seems that desiccation tolerance is not a trait which determines the vertical zonation of tropical seagrasses. Rather, it is hypothesised that the ability to tolerate high irradiances, as well as to benefit from high nutrient inputs from the shore, allows the shallow species to occupy the uppermost intertidal zone.
\end{abstract}

KEY WORDS: Desiccation - PAM fluorometry - Photosynthesis · Seagrass - Tropical

\section{INTRODUCTION}

Marine angiosperms, or seagrasses, are generally thought of as plants which grow submerged in seawater. However, several species grow in intertidal habitats where they are exposed to air for part of the day. This has been reported for temperate species of Zostera (Bulthuis 1995, Vermaat \& Verhagen 1996. Ramage \& Schiel 1998). On the physiological level, it was shown that both $Z$. noltii and $Z$. marina could maintain high rates of photosynthesis in air provided that their leaves were fully hydrated (Leuschner \& Rees 1993), but that such rates were negatively affected by water loss in a linear fashion (Leuschner et

-E-mail: mats.bjork@botan.su.se al. 1998). In addition, more tropical species can grow in the intertidal, where they often endure extreme conditions of high irradiance and a dry, desiccating, atmosphere (Jupp et al. 1996). Although emergence has generally been viewed as adverse for seagrass development (Yabe et al. 1995. Stapel et al. 1997), the physiological responses which underlie the potential of such tropical seagrasses to grow in the intertidal have not been studied before.

Unlike for seagrasses, physiological responses to air exposure have been studied extensively for intertidally growing marine macroalgae (see e.g a recent review by Davison \& Pearson 1996). Regarding desiccation, it was shown that species growing in the upper intertidal zone could maintain their photosynthetic rates at relatively low water contents of the thalli and/or that they possessed the ability to regain high rates of photo- 
synthesis shortly after re-submersion (Dring \& Brown 1982, Brown 1987, Einav et al. 1995). On the ecological level, it has long been considered that these and similar physiological responses (cf. Chapman 1966) reflect the different species' ability to occupy various niches along the vertical gradient of the intertidal zone. This finally results in the typical algal zonation pattern found in many intertidal areas.

Given the paucity of eco-physiological studies of tropical intertidal seagrasses, we set out to test the desiccation tolerances of several species from Zanzibar, East Africa. The present study is a continuation of previous ones initiated by Björk et al. (1997), who concluded that shallow-growing species in general possessed an efficient way of acquiring inorganic carbon from the seawater, including catalysed extracellular $\mathrm{HCO}_{3}{ }^{-}$to $\mathrm{CO}_{2}$ conversions and possibly also direct $\mathrm{HCO}_{3}{ }^{-}$uptake. Based on this, it was suggested that those species growing highest up in the intertidal zone were best adapted to utilise the abundant irradiance found there. In another study, it was shown that the 2 species growing highest up (Halophila ovalis and Halodule wrightii) were resistant to high irradiances as indicated by the fact that down-regulation of photosynthesis during a mid-day low tide was minimal (Beer \& Björk 2000). All measurements in both studies were carried out in water on fully hydrated plants, and no consideration was given to their hydration status during emergence. Here, we report on the photosynthetic performance of 8 seagrass species from Zanzibar during desiccation and following rehydration. This was done in order to investigate basic processes in response to emergence per se, but also in an attempt to find a physiological cause for their marked vertical zonation pattern within a tropical intertidal ecosystem.

\section{MATERIALS AND METHODS}

Study area. This study was performed at the Institute of Manne Sciences, University of Dar-EsSalaam, Zanzibar, Tanzania. Seagrasses were collected from the Mbweni Beach area located ca $5 \mathrm{~km}$ south of Zanzibar Town. The area is a large sand flat which is mostly exposed at low tide; the vertical tidal difference is up to $4 \mathrm{~m}$. The first seagrass species to emerge with the outgoing tide is Halophila ovalis. The second highest growing species is Halodule wrightii, followed by Cymodocea rotundata and Thalassia hemprichii, which only become exposed to air around spring tides. C. serrulata grows in the upper subtidal and Syringodium isoetifolium, Thalassodendron ciliatum and
Enhalus acoroides grow in deeper water. The vertical distribution of these species is depicted in Fig. 1.

Whole plants were collected at low tide, and kept in aerated seawater in dim light for a maximum of $3 \mathrm{~h}$ before experimentation. All experiments were carried out in the laboratory of the Institute of Marine Sciences, Zanzibar.

Experimental set-up. The electron quantum yield of photosystem II ( $Y$ ) was measured with a pulse amplitude modulated (PAM) fluorometer (the Diving-PAM, Waltz). This parameter was measured during steadystate photosynthesis in the light using the saturatingpulse method (Schreiber \& Bilger 1993) as $\left(F_{\mathrm{m}}{ }^{\prime}-F_{\mathrm{t}}\right) / F_{\mathrm{m}}{ }^{\prime}$ ', where $F_{\mathrm{m}}$ ' designates maximal fluorescence during an $0.8 \mathrm{~s}$ saturating light pulse, and $F_{t}$ is the steady state fluorescence at a given irradiance.

For desiccation experiments, a leaf of a specific seagrass was placed on a balance, with the main optical light guide of the PAM mounted ca $8 \mathrm{~mm}$ from, and at a $60^{\circ}$ angle to, the leaf surface. At that time, the fully hydrated weight (HW) was also recorded. The leaf was irradiated with a photosynthetic photon flux (PPF) of $500 \mu \mathrm{mol}$ photons $\mathrm{m}^{-2} \mathrm{~s}^{-1}$ at a temperature of $28^{\circ} \mathrm{C}$. Y was then recorded every minute together with the concomitant weight (CW) of the leaf. After the termination of each experiment, the dry weight of the leaf (DW) was determined after drying at $60^{\circ}$ for $24 \mathrm{~h}$, and its relative water content at each fluorescence measurement during the experiments was calculated as (CW-DW)/(HW-DW).

For the rehydration experiments, leaves were dried, under the same environment as in the desiccation experiments, to various pre-determined water contents ranging between 15 and $60 \%$. Each leaf was then

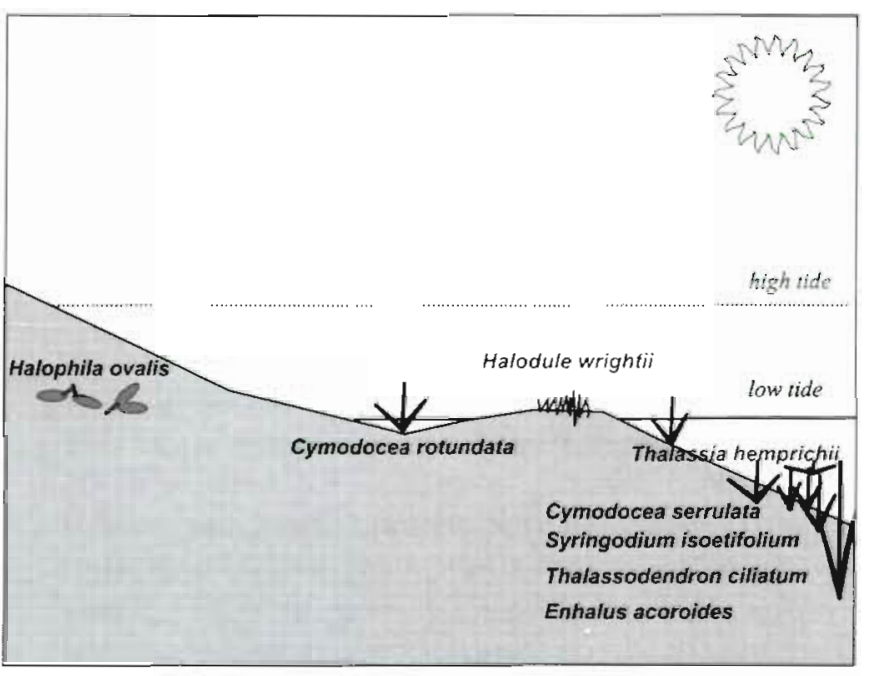

Fig. 1. Distribution of 8 seagrass species along the intertidaJ. and shallow subtidal depth gradient of Mbweni Beach, Zanzibar 
mounted on the light cable of the diving-PAM with the 'leaf distance clip' (Walz, Germany), which was then submerged in $28^{\circ} \mathrm{C}$ seawater at a PPF of $200 \mu \mathrm{mol}$ photons $\mathrm{m}^{-2} \mathrm{~s}^{-1}$. Y was measured every minute until stable values were obtained.
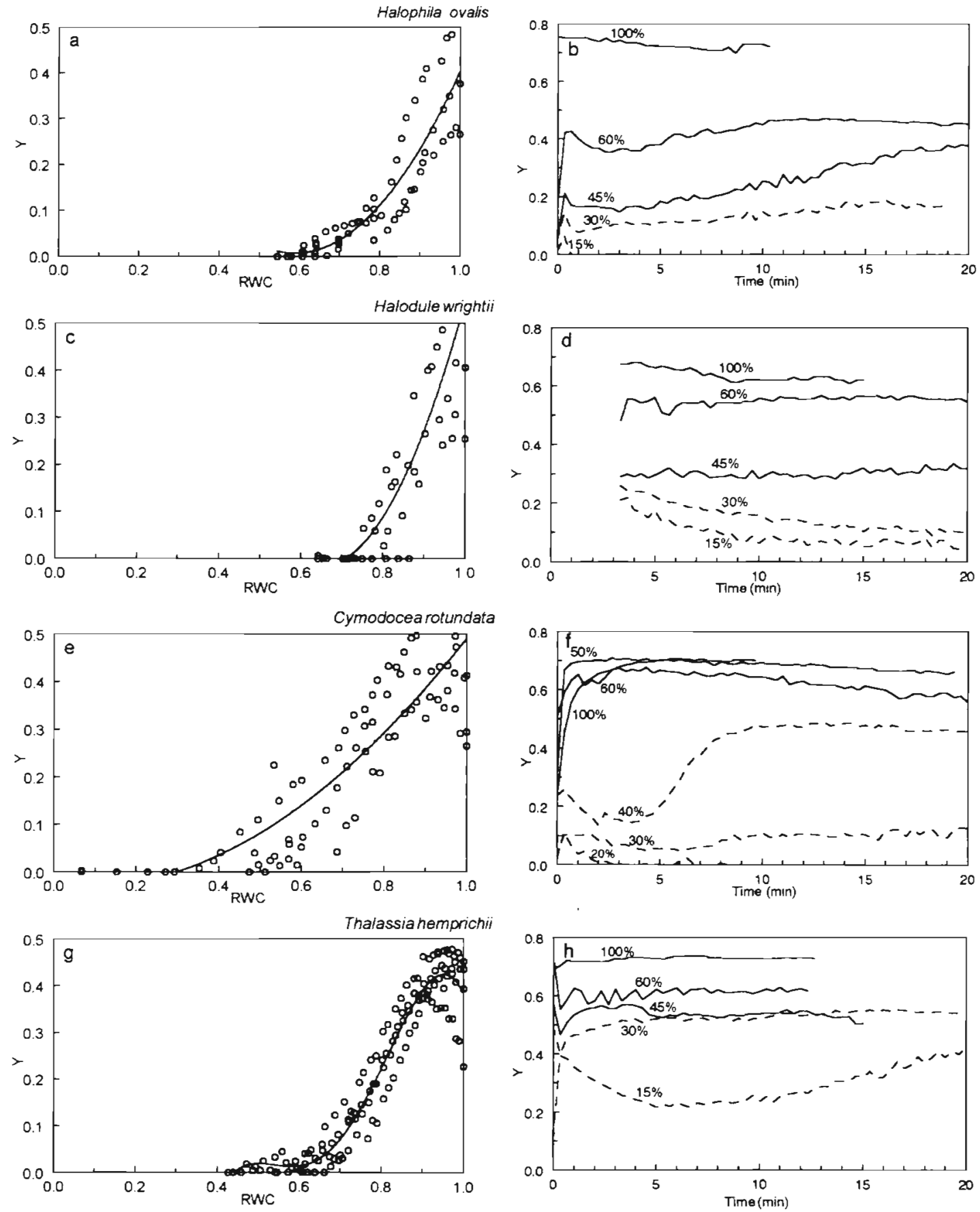

Fig. 2. (a,b) Halophila ovalis; (c,d) Halodule wrightii; (e,f) Cymodocea rotundata; (g,h) Thalassia hemprichii. Electron quantum yields of photosystem II (Y) as a function of relative water contents (RWC) of the leaves (left panel. 3 to 5 replicate leaves) during emergence, and $(b, d, f, h)$ after re-submergence following desiccation to predetermined water contents for various shallow-growing intertidal seagrasses 
growing species, was very sensitive to desiccation as indicated by a drop in $\mathrm{Y}$ to half its original value after losing only $10 \%$ of its water (Fig. 2a), and by not being able to regain the original activity after losing $40 \%$ (i.e. containing 60\%) water (Fig. 2b). Similar responses were obtained for Halodule wrightii (Fig 2c,d), but this plant showed a slightly higher tolerance to desiccation in that it was able to regain a higher $Y$ following a $40 \%$ water loss. Both Cymodocea rotundata and Thalassia hemprichii, growing in the lower intertidal zone, were more tolerant to desiccation. This is reflected in $50 \%$ of the $\mathrm{Y}$ remaining at a lower water content during desiccation (75 and 80\%, respectively; Fig. 2e,g), and by the ability to restore close to original $Y$ values after substantial water losses. Within this group, Thalassia hemprichii showed a remarkable capacity to regain close to its original $Y$ even after losing $85 \%$ water.

Cymodocea serrulata, an upper subtidal species, was relativity resistant to the effect of desiccation during emergence, but could not regain its original $Y$ after losing $55 \%$ water (Fig. 3a,b). The subtidal species Thalassodendron ciliatum and Enhalus acoroides showed even higher tolerances to desiccation as they were able to regain full Ys after desiccating to $45 \%$ of their original water contents (Fig. 3d,f). One difference between these 2 species was that $E$. acoroides was able to regain part of its photosynthetic activity after a water loss of $85 \%$ during re-submergence, while $T$. ciliatum seemed to be irreversibly damaged by this desiccation level. Syringodium isoetifolium was the only subtidal species which was very sensitive to desiccation. This is evidenced in a $50 \%$ drop in $\mathrm{Y}$ at less than $10 \%$ water loss, and the inability to regain close to a full $\mathrm{Y}$ after only a $40 \%$ water loss

A different measure of desiccation resistance is the time it takes for the leaves to lose water when exposed to the air. The time it took for leaves to lose $50 \%$ of their original water content was very similar for all species except Enhalus acoroides and Syringodium isoetifolium, which became desiccated at a

Table 1 . Time taken for leaves of the various seagrass species to lose $50 \%$ of their original water content (calculated as (CW-DW)/(HW-DW), see 'Experimental set-up'). The experiment was carried out in the laboratory at $26 \mathrm{C}$ and $75 \%$ relative humidity. Data are average of 5 replicates \pm SD

\begin{tabular}{|lc|}
\hline \multicolumn{1}{c}{ Seagrass } & Time (min) \pm SD \\
\hline Cymodocea rotundata & $10 \pm 3$ \\
Cymodocea serrulata & $11 \pm 4$ \\
Thalassodendron ciliatum & $11 \pm 4$ \\
Halodule wrightii & $14 \pm 2$ \\
Halophila ovalis & $14 \pm 3$ \\
Enhalus acoroides & $37 \pm 5$ \\
Syringodium isoetifolium & $45 \pm 3$ \\
\hline
\end{tabular}

much slower rate (Table 1 ). This is probably due to their leaves being much thicker than the leaves of the other species.

\section{DISCUSSION}

The various ways in which physiological desiccation tolerances of intertidal plants can be appreciated include measurements of photosynthetic rates during desiccation (Beer \& Eshel 1983, Leuschner et al. 1998) and following re-submersion (Beer \& Kautsky 1992). These are measured either $\mathrm{CO}_{2}$ (in air) or $\mathrm{O}_{2}$ (in water) exchange. In this work, PAM fluorometry was used to measure $Y$ (the effective quantum yield of photosystem II) of seagrasses being affected by desiccation. This was done since it had earlier been shown that rates of photosynthetic electron transport (ETR) based on measurements of $\mathrm{Y}$ were positively correlated with rates of photosynthetic $\mathrm{O}_{2}$ evolution in a number of species (Beer et al. 1998), including Halophila ovalis and Halodule wrightii (Beer \& Björk 2000). Because the ETR is principally derived from multiplying $Y$ with the irradiance level (Beer et al. 1998, Beer \& Björk 2000), it follows that $Y$ is proportional to $\mathrm{O}_{2}$ evolution at a constant irradiance. One advantage of PAM fluorometry over gas exchange measurements is that the plants need not be confined to enclosures. Thus, Y could here be measured repetitively while simultaneously estimating water contents by simply leaving a leaf on a balance throughout the time course of measurements.

Using $Y$ as a measure of the photosynthetic ability, we found no correlation between the desiccation tolerance of 8 tropical seagrass species and their vertical distribution along a depth gradient ranging from the upper intertidal to the shallow subtidal. For example, Halophila ovalis and Halodule wrightil growing in the upper intertidal were among the least tolerant species while Thalassodendron ciliatum and Enhalus acoroides from the subtidal were among the most tolerant ones. There is only 1 other investigation in which correlations between desiccation responses and growth habitat of seagrasses has been indicated. Leuschner et al. (1998) found that the temperate Zostera noltti, which grew on more elevated sites in the intertidal of the German Wadden Sea than did Z. marina, maintained high photosynthetic rates at lower leaf water contents than did the latter. However, no comparison was made between the species regarding their capacity to regain photosynthetic activity during re-submersion. Our results are unlike those for marine macroalgae, where a positive correlation between physiological adaptations to emergence and vertical zonation is often present. In particular the capacity to regain high rates of gas exchange upon re-submersion following desiccation was 
found to correlate with the ability of temperate algae to grow at an elevated position in the intertidal (e.g. Dring \& Brown 1982). For example Fucus spiralis, growing in the upper intertidal, was able to tolerate desiccation better than other Fucus species growing lower down
(Beer \& Kautsky 1992). For the seagrasses studied here, as well as 3 species of Fucus (cf. Beer \& Kautsky 1992), the rates of water loss did not indicate that species of the upper intertidal possessed any special means to reduce water loss from the leaves.
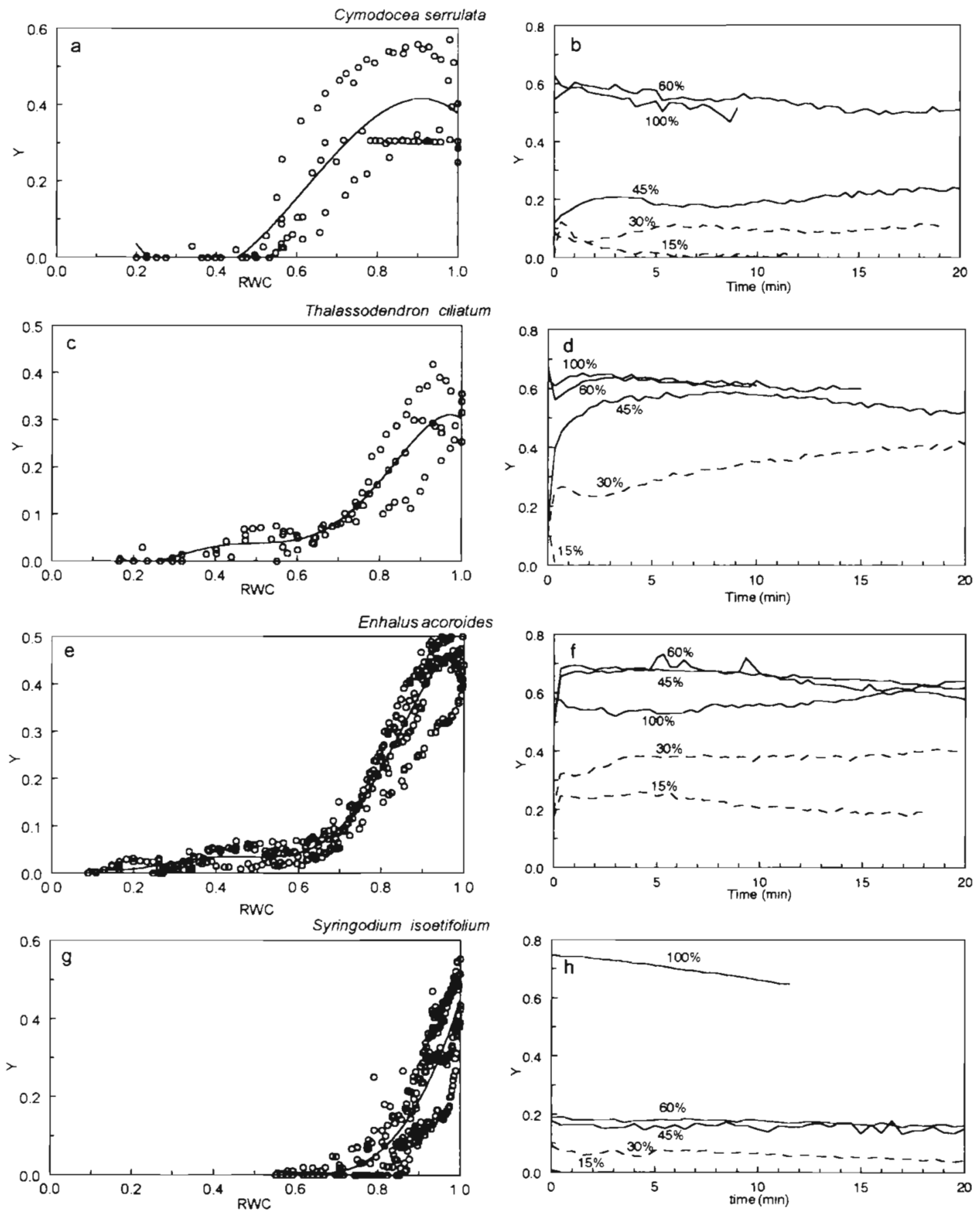

Fig. 3. (a,b) Cymodocea cerrulata; (c,d) Thalassodendron ciliatum; (e,f) Enhalus acoroides; (g,h) Syringodium isoetifolium. Electron quantum yields of photosystem II (Y) as a function of relative water contents (RWC) of the leaves (a,c,e,g, 3 to 5 replicate leaves) during emergence, and $(b, d, f, h)$ after re-submergence following desiccation to predetermined water contents for various deeper-growing intertidal and subtidal seagrasses 
The results of this study indicate that even though seagrasses do grow in the tropical intertidal, physiological adaptations to prevent or endure water loss are not traits which determine these plants' ability to grow in this habitat, and are therefore not a cause for the vertical zonation pattern. Given that the 2 uppermost growing species showed the highest sensitivity to desiccation, one may ask how they can survive air exposure at all during low tides? We observed that these plants, although growing under emergent conditions for several hours a day, may actually not desiccate much in the field. For Halophila ovalis, this is because the leaves are supported by thin and flexible petioles which allow them to bend down so as to lie flat against the sand when the water retreats during low tide. This sand is always kept moist by pore-bound seawater and by water seepage from higher elevations on the shore. In addition to being thin and flexible, the often densely growing leaves of Halodule wrightii also cover one another during low tide so as to reduce evaporation from those leaves not lying directly on the moist sand. Thus, it seems that it is the ability of these seagrasses to 'avoid' excessive water loss (rather than coping with it on the physiological level) that enables them to evade the otherwise detrimental effects of desiccation. In contrast, it is suggested that the deeper-growing species which have larger and more erect leaves would be affected more directly by the desiccating atmosphere if they were to be exposed to air. Indeed, those parts of the leaves of Cymodocea rotundata and Thalassia hemprichii which became air-exposed during extremely low tides died.

If there is no physiological adaptation to desiccation, what is it then that allows the thin-leafed Halophila ovalis and Halodule wrightii to grow preferentially in the upper intertidal? In a previous study it was found that these 2 species could utilise inorganic carbon very efficiently (Björk et al. 1997). This notion was supported by the observation that they were well adapted to tolerate the high irradiances found in situ as indicated by the low extent of photosynthetic down-regulation during the high ambient mid-day irradiances (Beer \& Björk 2000). In addition, at the site where this investigation was conducted, these plants may have benefited more than other species from the nutrient-rich runoff water seeping through the sand of the upper intertidal. This is because they are smaller, and thus have a shallower root system than the larger species, which would limit their nutrient supply if they grew farther away from the shore.

Acknowledgements. A.W. and S.B. wish to thank R. Weil, Stockholm, and M.B. and J.U. thank SAREC/Sida, for continuing support of this research.

\section{LITERATURE CITED}

Beer S, Björk M (2000) Measuring rates of photosynthesis of two tropical seagrasses by pulse amplitude modulated (PAM) fluorometry. Aquat Bot 66:69-76

Beer S, Eshel A (1983) Photosynthesis of Ulva sp. I. Effects of desiccation when exposed to air. J Exp Mar Biol Ecol 70: 91-97

Beer S, Kautsky L (1992) The recovery of net photosynthesis during rehydration of three Fucus species from the Swedish west coast following exposure to air. Bot Mar 35 : $487-491$

Beer S. Vilenkin B, Weil A, Veste M, Susel L, Eshel A (1998) Measuring photosynthetic rates in seagrasses by pulse amplitude modulated (PAM) fluorometry. Mar Ecol Prog Ser 174:293-300

Björk M, Weil A, Semesi S, Beer S (1997) The photosynthetic responses of eight seagrass species from Zanzibar to increased inorganic carbon concentrations. Mar Biol 129: 363-366

Brown MT (1987) Effects of desiccation on photosynthesis of intertidal algae from a southern New Zealand shore. Bot Mar 30:121-127

Bulthuis DA (1995) Distribution of seagrasses in a north Puget-Sound estuary-Padilla Bay, Washington, USA. Aquat Bot 50:99-105

Chapman VJ (1966) The physiological ecology of some New Zealand seaweeds. Proc Int Seaweed Symp 5:29-54

Davison IR, Pearson GA (1996) Stress tolerance in intertidal seaweeds. J Phycol 32:197-211

Dring MJ, Brown FA (1982) Photosynthesis of intertidal brown algae during and after periods of emersion: $a$ renewed search for physiological causes of zonation. Mar Ecol Prog Ser 8:301-308

Einav R, Breckle S, Beer S (1995) Ecophysiological adaptation strategies of some intertidal marine macroalgae on the Israeli Mediterranean coast. Mar Ecol Prog Ser 125: $219-228$

Jupp BP, Durako MJ, Thayer GW, Schilak L (1996) Distribution, abundance, and species composition of seagrasses at several sites in Oman. Aquat Bot 53:199-213

Leuschner C, Rees U (1993) $\mathrm{CO}_{2}$ gas exchange of two intertidal seagrass species, Zostera marina L. and Zostera noltii Hornem., during emersion. Aquat Bot 45:53-62

Leuschner C, Landwehr S, Mehlig U (1998) Limitation of carbon assimilation of intertidal Zostera noltii and $Z$. marina by desiccation at low tide. Aquat Bot 62:171-176

Ramage DL. Schiel DR (1998) Reproduction in the seagrass Zostera novazelandica on intertidal platforms in southern New Zealand. Mar Biol 130:479-489

Schreiber U, Bilger W (1993) Progress in chlorophyll fluorescence research: major developments during the past years in retrospect. In: Dietmar BH, Heidelberg UL, Darmstadt KE, Kadereit JW (eds) Progress in botany. Springer-Verlag, Berlin, p 151-173

Stapel J, Manuntun R, Heminga MA (1997) Biomass loss and nutrient redistribution in an Indonesian Thalassia hemprichii seagrass bed following seasonal low tide exposure during daylight. Mar Ecol Prog Ser 148:251-262

Vermaat JE, Verhagen FCA (1996) Seasonal variation in the interticlal seagrass Zostera noltii Hornem: coupling demographic and physiological patterns. Aquat Bot 52: $259-281$

Yabe T, Ikusima I, Tsuchiya T (1995) Production and population ecology of Phyllospadix iwatensis Makino. 1 Growth and biomass in an intertidal zone. Ecol Res 10 : $291-299$ 